This item was submitted to Loughborough's Research Repository by the author.

Items in Figshare are protected by copyright, with all rights reserved, unless otherwise indicated.

\title{
Pillar or platform - A taxonomy for process improvement activities in public services
}

PLEASE CITE THE PUBLISHED VERSION

http://dx.doi.org/10.1080/09540962.2018.1389487

\section{PUBLISHER}

(C) 2017 CIPFA. Published by Taylor \& Francis

\section{VERSION}

AM (Accepted Manuscript)

\section{PUBLISHER STATEMENT}

This work is made available according to the conditions of the Creative Commons Attribution-NonCommercialNoDerivatives 4.0 International (CC BY-NC-ND 4.0) licence. Full details of this licence are available at: https://creativecommons.org/licenses/by-nc-nd/4.0/

\section{LICENCE}

CC BY-NC-ND 4.0

\section{REPOSITORY RECORD}

Bateman, Nicola, S. Lethbridge, and A. Esain. 2019. "Pillar or Platform - A Taxonomy for Process Improvement Activities in Public Services". figshare. https://hdl.handle.net/2134/24777. 


\title{
Pillar or Platform - A Taxonomy for Process Improvement Activities in Public Services
}

\begin{abstract}
Research in the area of lean in public services, and particularly implementation, needs to develop from reporting individual cases to provide a taxonomy that can be taught and applied by researchers and practitioners. The purpose of this paper is to outline two main approaches to Process Improvement Activities (PIA). This will provide researchers with a model to study lean implementation and practitioners with a decision-making taxonomy when designing lean implementations.
\end{abstract}

The paper proposes two PIA approaches, Pillar and Platform, and tests the validity of these approaches through two organisational case studies. Within these case studies, 96 PIAs are considered. For each of the cases, the degree to which the taxonomy supports decision making is explored and issues associated with each implementation approach are discussed. The paper finds that Pillar and Platform taxonomy can be used as a metaphor for practitioners to better understand choices when planning a programme of process improvement particularly based on the organisation's lean maturity.

\section{Introduction}

This paper provides researchers with a taxonomy for organisations implementing lean, particularly at the operational level. It aims to aid managerial decision making when planning a lean programme by defining and testing two different approaches to Process Improvement Activities (PIA) within lean implementations (Womack and Jones, 2003). The paper addresses a common dilemma for managers starting the adoption of lean, of 'where to start?' and project selection (Bumblauskas, and Meyer (2015) which has limited attention in the literature despite Senge (1990) and Elger and Smith (1994) presenting the positive attributes of workforce mobilisation through PIA and a lean approach.

The diffusion of Lean for increasing value for service-users through improved service delivery in organisations is widely reported (Piercy and Rich, 2009). For many organisations, PIA's form the first hands-on activities with which to start a lean journey (Rother, 2010). This paper builds on two briefly outlined alternatives for the introduction of PIA into an organisation, the Pillar and Platform (Hines, Bateman and Hudson, 2004).

This paper aspires to build on the area of public service-dominant logic to support a more considered use of PIA's as public sector organisations are identified as placing an "over reliance" on the use and implementation of PIA’s (or RIA) (Radnor, Osborne 2013). The paper focuses on the relationship between implementation choice and desired outcome, to explore the Research Questions (RQs):

1. How well does the Pillar and Platform taxonomy provide a model for organisation wide PIA's?; thus

2. What are the implications of choices between Pillar or Platform approach for managers?

\section{Literature of lean maturity and PIA implementation}

The use of lean approaches is well established in lean and practitioner literature and PIAs were popularised in the UK in the 1990's as a way to achieve high performance (Joynson and Forrester, 1995). The purpose of a PIA is to improve a defined area by applying techniques using teams of people who work in that area. PIA are also known as Kaikaku (Womack and Jones, 2003); Kaizen Events (Imai, 1986; Bateman and David, 2002); Kaizen Blitz ( Laraia et al., 1999); workshops (Rother, 2010); and rapid improvement events (Fillingham, 2008). While labels used to describe PIA may vary, the underpinning assumption is as part of lean implementation to improve processes and systems in line with customer value, has remained constant (Womack and Jones, 2003).

The term Pillar and Platform originates with the authors and exemplify two PIA approaches. The terms emerged from implementation practice specifically the Learn 2 research project (Rich et al., 2006) and were coined to reflect the two approaches observed: one was described as Pillar i.e. narrow in geographical focus yet involving in-depth implementation; the other as Platform i.e. wide in geographical focus yet focusing on only one or two tools. However, whilst the terms became part of linguistic currency, neither concept was fully defined. Consequently this paper attempts to remedy this lacuna. The choice of Pillar and Platform appears to be influenced by the level of organisational maturity in lean terms and attributes of maturity in five stages identified Esain et al, 2011 of point, point to process, process, holistic and end to end are useful here. 


\section{The Pillar and Platform Definition}

The definition of the Pillar and Platform approaches to PIA implementation are intended to outline ways in which PIAs are initiated and spread within an organisational structure. Organisations often employ division of work, the objective of which is 'to produce more and better work with the same effort' (Fayol, 1916; in Pugh 1990). Within lean paradigm, this division of labour is linked to form value streams (Womack and Jones, 1996). The Pillar and Platform metaphor describes two alternative ways of addressing PIAs in value streams (Figure 1).

The principle differences between Pillar and Platform implementations are of size and scope. 'Size' is the geographical boundary of implementation of the PIA. 'Scope' refers to the number of different lean tools employed and the depth of their use. Pillar activities have a narrow geographical size and are deeper scope, whereas Platforms have more extensive geographical size and are more limited in scope. This is illustrated in Figures 1, which show a comparison of the 'before' implementation (a) and two alternative 'afters' representing the Platform approach or Pillar approach. Figure 1a, shows an administrative organisation with three parallel value streams, each value stream having three stages. It has two support functions (such as IT) one affects two value streams the other all three.
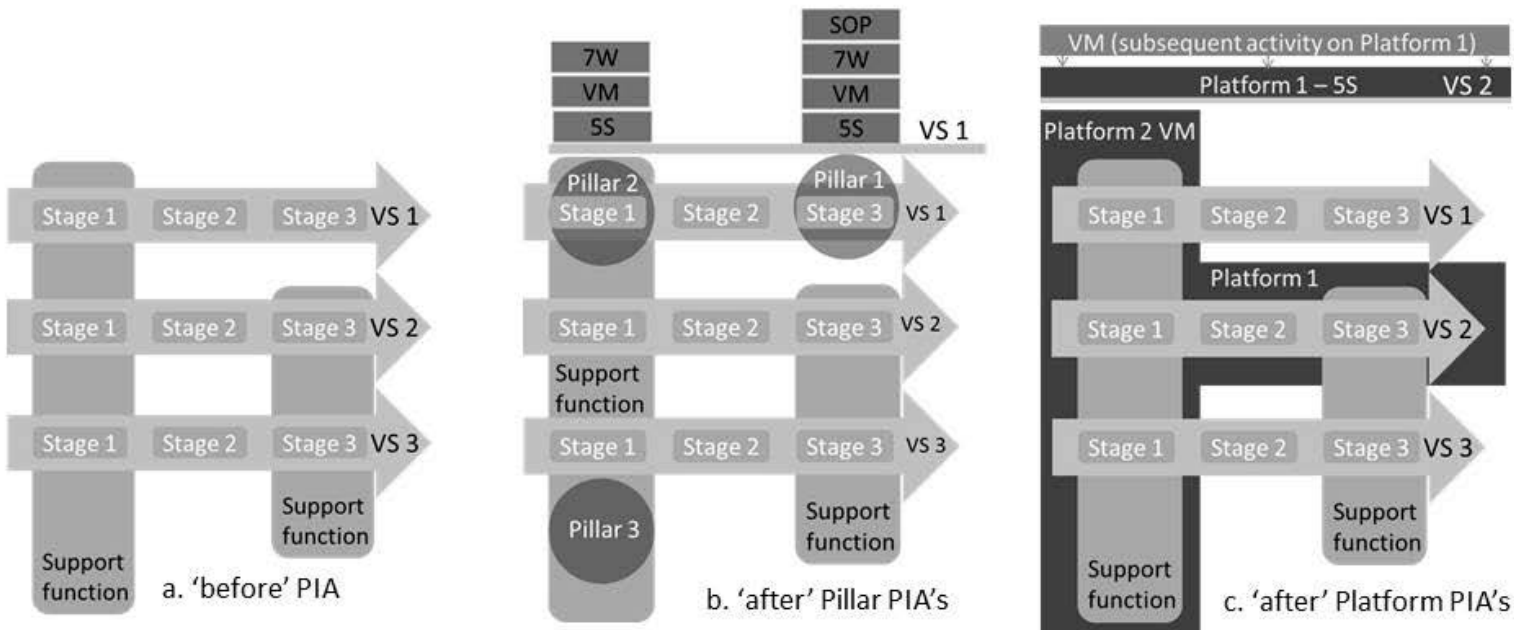

Figure 1: An administrative organisation, 'before' plan view and 'after' Pillar and Platform PIAs

A Pillar activity would seek to apply a range of tools such as 5S (workplace organisation), Visual Management (VM), 7 Waste analysis (7W), and Standard Operations (SOP) in a small functional area such as stage 3 in value stream 1 (VS 1) in Figure 1b. The organisation might then go on to apply further Pillars in areas such as stage 1 on VS 1 and support functions as required. The cross section view shows the 'build-up' of these tools along VS1. The Pillar approach's rationale is to achieve as much as possible of the lean approach in a small area, by the application of a wide range of tools i.e. wider scope.

A Platform activity would seek to apply just one or two tools (e.g. 5S) in a wider area. The Platform would then focus on another lean tool such as visual management as a subsequent activity. Hence the Platform approach's rationale and strategic intent is to spread across boundaries to new areas for example along value streams.

Figure 1c shows the example organisation applying 5S across all the stage 5's in the value streams, then moving on to VM along VS 1 and then addressing the whole of a large support function with platform 2.

Comparing the cross section views from Figure $1 \mathrm{~b}$ and c shows the difference in size and scope for the two approaches. Platform 1 addresses all of VS 2 whereas Pillars 1 and 2 apply a deeper scope of lean tools in two parts of VS 1. Teaching tools as discrete elements allows people new to lean to understand the tools, however, as people participate in PIA's they become more familiar with a range of tools, and realise they overlap. This is part of individuals gaining a deeper understanding of how the tools support each other. This opportunity occurs more frequently in a Pillar activity compared to a Platform.

Pillars therefore allow substantial benefits to be demonstrated within the limits of the selected area. It is characterised by short intensive activities focused in a small area, with no or limited subsystem boundaries crossed. These are sometimes referred to as ‘islands of excellence’ (Hines, Holweg and Rich, 2004). This is not intended to imply that spread is not desired, rather the process of spread will often be ad hoc and opportunistic rather than purposeful. Spread, in this instance, relies on co-operation between managers. 
Platforms approach application of tools in a different way. They principally focus on a single tool and anticipate bringing in additional tools at a later date. This means that effort is focused on spreading that tool across boundaries and enables cross-functional involvement of teams. Implicitly, the issue of cooperation across managers should be in place for this type of PIA to commence. An operational objective for using a Platform approach is to encourage peers to work consistently and co-operatively. A managerial objective could be to improve the performance of the value stream and lay the foundations for further improvement.

\section{Methodology}

The Pillar and Platform concepts were defined in section 3. Two in-depth cases were then studied where both Pillars and Platforms were present, helping evaluate the Pillar and Platform definitions. The Pillar and Platform models were compared against the case findings and differences explored in the Discussion (see section 6), thus addressing research questions 1 and 2. Therefore, this research utilises a case study research design (Yin, 1994) underutilised in operations management (Voss, et al. 2002) yet important for theory building (Eisenhardt, 1989).

Case selection was by determined variables relevant to the research questions (Miles and Huberman, 1994); that of a large organisational size and lean immaturity along with the longitudinal nature of observation. Thus the study is able to assess the implications of the 'where to start' decision (enabled by lean immaturity) and how this affects organisations over time gives opportunity for multiple observations of PIA's. For simplicity the cases were drawn from health care and higher education in a single country (UK) setting.

\section{Case Studies}

The UK has been at the forefront of New Public Management (NPM) whereby the past strategic philosophy of democratic control and public accountability is replaced with a focus on value for money, efficiency, performance management, transparency and contestability, often in the form of audit (Pollitt and Bouckaert, 2004). It is therefore not surprising that Public Services in the UK have drawn on approaches, such as lean, applied in other sectors (Young, 2004) as the solution to the performance challenges they face. The case organisations are drawn from the public sector are representative in their domains of higher education and public healthcare. Radnor et al. (2006) indicated that within the UK public sector, healthcare is a leading proponent of lean. Similarly, Higher Education institutions (Hines and Lethbridge, 2008) have also initiated improvement programmes in the last ten years and their selection for study was purposeful due to the similarity of organisational attributes.

The specific organisations were also selected as they have comparable organisational attributes such as: high numbers of employees and large budget; brown field organisations with many years' history; and extensive history of structural change (Table 1).

Table 1: Context of Case Studies Source: Authors

\begin{tabular}{|l|l|l|}
\hline & Case 1: University & Case 2: Healthcare \\
\hline $\begin{array}{l}\text { Representative } \\
\text { of the sector }\end{array}$ & $\begin{array}{l}\text { Member of the 'Russell Group’ of } \\
\text { Universities. Primary focus is research. } \\
\text { Turnover of } £ 429 M\end{array}$ & $\begin{array}{l}\text { Representative of UK region (i.e. average } \\
\text { outpatient attendance, day cases attendance, } \\
\text { length of stay for inpatients, bed capacity, }\end{array}$ \\
\hline Maturity & $\begin{array}{l}\text { Initial experimentation - point Esain et } \\
\text { al, } 2011\end{array}$ & $\begin{array}{l}\text { Initial experimentation - point Esain et al, } \\
2011\end{array}$ \\
\hline $\begin{array}{l}\text { Length of } \\
\text { Study }\end{array}$ & $2006-2011$ & $2002-2007$ \\
\hline No of PIA’s & 40 & 56 \\
\hline Respondents & $\begin{array}{l}\text { Cross Functional work groups and } \\
\text { middle management }\end{array}$ & $\begin{array}{l}\text { Cross Functional work groups, facilitators, } \\
\text { middle managers and professionals. }\end{array}$ \\
\hline
\end{tabular}

The first case is a Higher Education (HE) organisation with 28,000 students and 6,000 members of staff. It is a member of the Russell Group, corroborating its status as a centre of research excellence. In September 2006, the HE organisation initiated a three year project to introduce lean thinking to become a 'top 50' world leading University within the Shanghai Jiao Tong Index by 2020. The second case organisation is from Healthcare and provides services to approximately 550,000 people through secondary care (hospitals) and a range of community health services. The organisation sought to increase the pace of change so that new ideas were welcomed and implemented without prevarication. It began a lean journey in 2002 and continues today. 


\section{Findings}

The findings present the two cases in a narrative form to show how the case organisations progressed through different types of Pillar and Platform implementations summarised in figures 2 and 3.

\section{Case 1: Higher Education}

The Lean University project was commissioned in 2006 by the University's Vice Chancellor. It was decided that the Lean University projects would fall into two categories: a series of 'Strategy' projects that were designed to create strategic alignment across the University; and 'End to End' projects, or 'value stream' projects, which would seek to improve the core of University activity (Hines and Lethbridge, 2008). Examples of these end to end projects include:

i) the procurement of external services and the payment of these services (Procure to Pay)

ii) the creation, maintenance and closure of teaching programmes (Programme approval);

iii) the creation, maintenance and closure of research projects;

The end to end category, it was hoped, would involve the majority of a University's workload and the first activity was 'Procure to Pay' which would be classified as a Platform in the taxonomy proposed - Figure 2. Before this project been completed a second 'end to end' project was initiated, 'Programme Approval'. Programme Approval involved the identification of an electronic solution, this then initiated a new externally funded programme to investigate and deploy a suitable IT product. Again before completion of the second project the final end to end project was initiated - 'Supporting Research Funding'. Progress in these initial end to end projects was very difficult, perhaps because they ran concurrently.

Each of the 27 schools in the University plus the 25 Directorates (central divisions of the University such as Registry, Finance, Marketing ) were affected by all three end to end projects. Consequently, securing senior management commitment and communicating the need for change and then implementing these changes, was a substantial task. No single person within either the Central Lean Team or the team of lean researchers had any managerial authority over any aspect of the process. Consequently, the teams relied on the managers that were part of the project teams to take responsibility to lead the actions going forward.

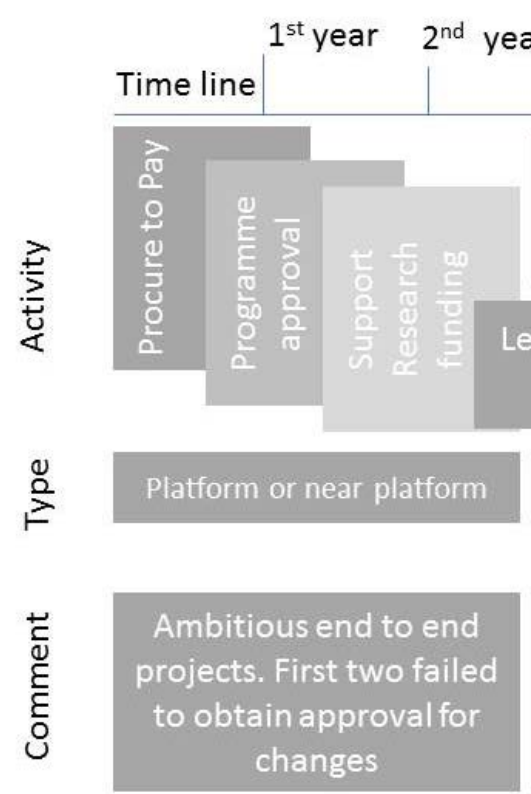

Figure 2: Summary of Higher Education PIAs
In terms of the 'strategy' set of projects, the experience was similar. The first attempts to define vision and objectives within different sections of the University were too large to successfully contemplate given the lack of organisational readiness. In the face of these challenges the Lean University programme shifted to educating key University managers in lean concepts and tools (Figure

2Error! Reference source not found.). The original lean University Masterplan identified the need for organisational 'lean Champions' and these individuals would work within

Schools and Directorates, have a 'day job', but would be

trained in the lean approach. These people would then act as key participants of larger projects and help to embed lean ways of working. On reflection, this learning programme of activity should have commenced earlier, however, team members were very busy working on the 'end to end' projects and were therefore unable to dedicate the time to getting a training programme running.

Training material was developed and key School Managers (the administrative heads of every School) were identified to be part of the programme. A project-based learning approach was adopted, whereby lean skills and 
concepts would be transferred through practical application. Each participant was asked to pick a small project, to take place within an area where they had control, in order to try out new lean skills. This approach inevitably involved the development of more PIA 'Pillars'.

Shifting to a programme where the managers themselves conducted the improvement activity began to increase involvement and commitment to the programme. As people running the projects had line managerial authority in the area being 'improved', teams seemed more likely to complete their actions. Strategy projects also worked well using this approach. Once key university individuals and lean activity could see the benefit of a lean approach, they were keen to create an area of improvement that resembled a 'Pillar' within their work area.

The 'Lean Skills for Managers' programme has now trained at least eight cohorts of key University managers. Project completion has not been entirely successful, but the Pillar projects have created a network of lean champions upon whom, Platform implementations could be attempted. The Pillar work that was successful proved the power of a lean approach and helped managers to employ lean concepts and tools as part of their management approach. These improvements were not going to dramatically bring about a revolution in the efficiency and effectiveness of University processes end to end, but they were essential in terms of building confidence and competence in the lean approach.

\section{Case 2: Healthcare}

The Trust Chairman was keen to improve the pace of change within the Trust, and lean was selected as the methodology for strategic change. Initially, a team of two Trust staff (not full time) were seconded to be responsible for the deployment of the programme. This team was led by the Financial Director as the lead for the Trust's Board.

The initial PIA was a pilot to prove the suitability for adaption from an industrial context to a complex service environment, the approach taken was a Pillar. The successful impact of the first PIA in the eyes of the sponsor led to a series of Pillar PIA's being implemented across the organisation (Figure 3). These were not linked to the strategic direction of the organisation, but were motivated by short-term tactical needs. Consequently, early PIA's did address highly visual, tactical, disruptive issues such as the rising cost of temporary labour. These early PIA's were deemed successful against the desire to improve the speed of change with tangible benefits achieved against the PIAs objectives.

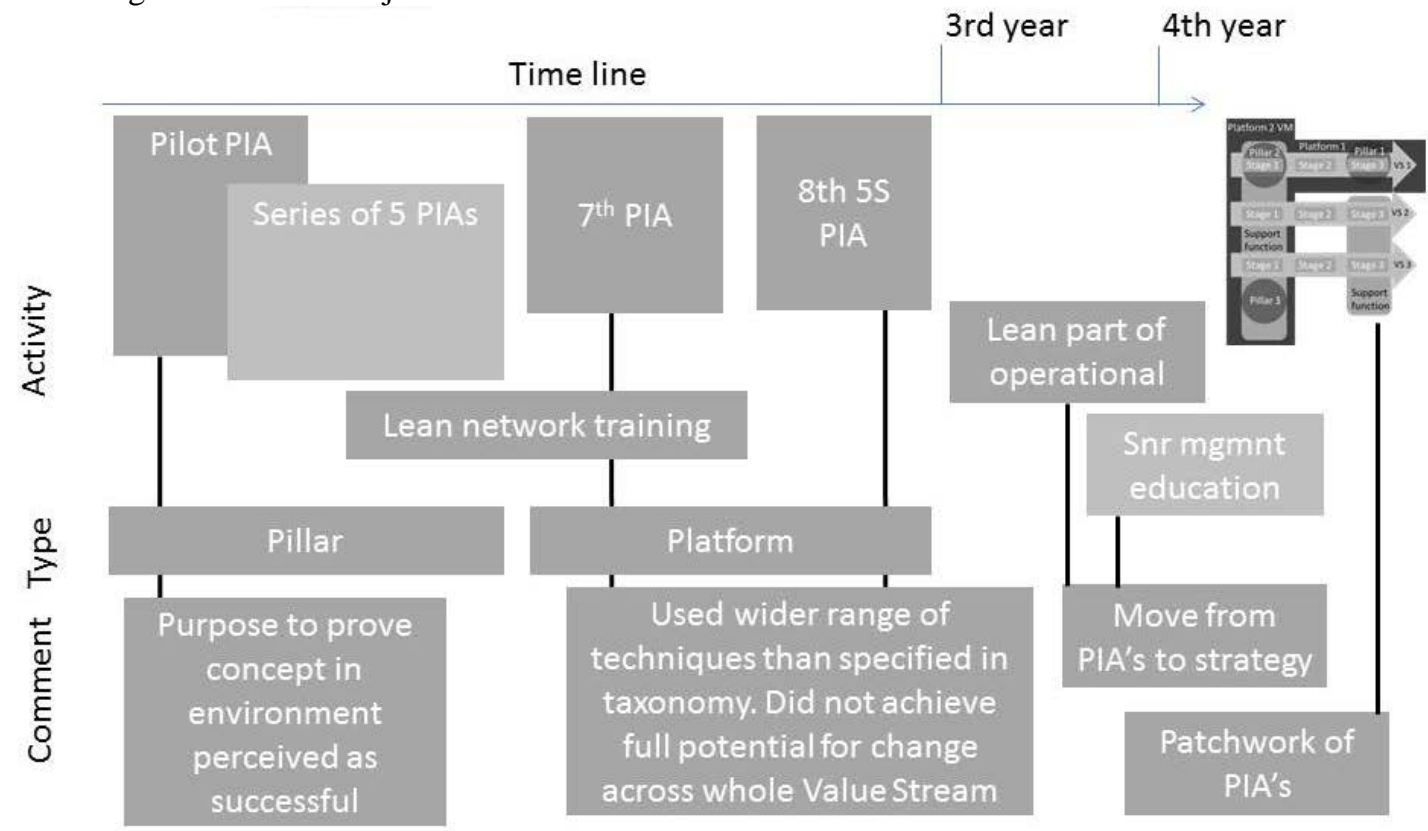

Figure 3: Summary of Healthcare

In addition to the Lean Team of two, a wider lean network was initiated. The purpose of this network was to spread the commitment to the programme, open routes of communication build capacity and engage middle management. The Network was populated by individuals nominated to represent all directorates and departments of the Trust. Individuals were briefed to confirm the role of individuals, including responsibility for communication in their specialist area and the individuals' commitment to become involved in PIA's was discussed. Training was made available to this group and it was anticipated that this would in turn lead to 
training of others within their areas of responsibility. This group met four times a year to formally share practices and to start to link the PIA's with the strategic objectives of the organisation

At this time, all the PIA's that took place in support functions and were Pillars. These Pillars did, however, cross functional boundaries because support functions tended to provide services to other internal functions and it was deemed important that 'customers' voice be included. The seventh PIA (general surgery) represented the first step change in the decision making process for the sponsor at senior management level. The geographical size of the $7^{\text {th }}$ PIA on one site was delivering general surgical care, from the point of patient referral to the point of patient discharge, and therefore would be classified as a Platform (Figure 3). The scope included a combination of techniques, but like the first PIA in the Higher Education, this PIA failed to achieve the full potential for change, but did achieve improvement against tasks which were within individuals' span of control.

The rate of PIA's being introduced in the organisation doubled over two years, reflecting an increase in demand (pull) from the organisation. At this time, both Platforms and Pillars were being used in tandem and the selection of each approach was based on the size of the PIA and where functional boundaries lay. The next major shift took place not long after the general surgery $\left(7^{\text {th }}\right)$ PIA. The sponsor and Lean Team (now increased in full time staff) decided to adopt a Platform strategy using 5S and Problem Solving. The purpose of this Platform PIA (no. 8) was principally to meet the demand from the organisation, to widen the use of lean tools (Error! Reference source not found.). This shift also recognised the need for capacity building outside of the lean network, to enable change for the future. In addition, the enthusiasm to make changes to work routines led to PIA's which were being randomly enacted through individual enthusiasts from their own intuition, rather than as part of a top down plan.

In the third year of lean implementation, the organisation started to include lean in its strategy and as part of its operational plan (Figure 3). All people directly reporting to the CEO were expected to have an objective in their personal appraisals that included a lean approach. In the fourth year of PIA's, the senior management team recognised gaps in their own knowledge and so an educational programme was deployed (Figure 3). This approach was grounded in the idea that lean needs to be enacted not only at the level of the PIA, but also at the organisational level. The capacity building was being linked at an individual level (by enthusiasts), at the PIA level (both Pillar and Platform) and at senior management level.

Considerable progress had been made in improving the speed of change, but it was considered that success was only being achieved in limited areas of the Trust and these projects were not very joined up. This gave the impression of a patchwork of PIA's, (Figure 3) with gaps resulting in frustration by those involved and potential issues with sustainability. In addition, the complex nature of healthcare provision means that PIA's within the confines of the Trust needed to be considering whole patient flows. For example a pillar PIA in the scope of general medical services, also involved social services.

\section{Discussion}

The purpose of characterising the Pillar and Platform approaches is to allow managers to make informed decisions about the best approach for PIA. The Review of Pillar and Platform Taxonomy section below considers how well the Pillar and Platform taxonomy provides a model for PIA's (RQ1) and the next section Managerial implications of choice between Pillars and Platforms considers the factors from the research that managers in large public sector organisations should consider (RQ2). Thus addressing some of the issues raised in (Radnor, Osborne 2013) “A focus and over-reliance on Lean workshops ('Rapid Improvement Events'), A tool-kit based approach to Lean implementation, but without an understanding of the key principles or assumptions,". The final section considers implications for practice.

\section{Review of Pillar and Platform Taxonomy}

The Pillar taxonomy is well represented in each case (figures 2 and 3), with Higher Education resorting to a narrow geographical focus when a larger Platform approach proved too ambitious. Healthcare used Pillar as a starting point to prove the lean approach in a sceptical environment. There were some subtle moves away from the Pillar model in the Healthcare case where Pillars took place in support function and the Pillars did cross functional boundaries, but in a way that addressed how these support functions provided services to other functions rather than a major modification to the other functions. So in essence it remains a Pillar as defined previously.

Examples of Platforms that conformed well to the model outlined were reported in initial activities for Higher Education and the $8^{\text {th }}$ PIA in the second year of the Healthcare case. The first Platform in the Healthcare case ( $7^{\text {th }}$ PIA) employed "a combination of techniques", thus exceeding the definition outlined in this paper by 
encompassing both large geographical size and scope in terms of tools and techniques. Thus the cases demonstrate that the Pillar and Platform taxonomy provides a way of thinking about PIA applications, but other configurations are possible with a spectrum of 'hybrids' such the $7^{\text {th }}$ Healthcare PIA.

\section{Managerial implications of choice between Pillars and Platforms}

Associated with the different Pillar or Platform approaches are risks related to achieving improvements desired and complexity of implementation. These attributes posed in the RQ2 with regard to the implications of choices between Pillars and Platforms. These implications focus on speed of impact, lean maturity and strategic alignment.

Speed of impact, span of control and risk are affected by the political imperative on managers to implement change and improvement quickly, shown particularly in the Healthcare case makes the adoption of a Pillar approach attractive and ultimately more feasible. The case studies have indicated that Pillar activities are more practical where little pre-existing learning or experience of PIA's exist. This occurs in the Healthcare case - for their first 6 PIA's and, having initially implemented less successful Platforms, Higher Education reached the same conclusion.

Platforms, by their definition, require a broader geographical span of managerial control than Pillars. The early Platforms undertaken at Healthcare and Higher Education encountered problems in this area. For example, in Healthcare the $7^{\text {th }}$ PIA did not engage well with the doctors. Similarly, the ambitious 'end to end' PIA's for Higher Education failed to achieve as they affected 'so many people'.

In terms of lean maturity the cases took place in organisations that were in their first stages - initial experimentation according to Table 1 , and so there had been little previous requirement for management to think about sequencing along values streams to enact continuous flow (Womack and Jones, 2003). The desire to implement end to end value streams in Higher Education was constrained by the lack of cohesive middle management along values streams. This meant that the case organisations, whatever their aspirations may have been, had to face their management shortcomings in experience and knowledge before they were able to properly implement Platforms. Whereas Pillars, because of the smaller span of control required, can fit into a management structure that does not support value streams and thus are lower risk.

The cases have indicated that it is generally more possible to introduce localised learning required to support Pillars than the cross functional management experience to support Platforms. The two cases both took place in organisations without experience of PIA's, and so organisations with greater experience have greater choice of PIA approaches. In both cases the organisations had to address this by introducing lean education programmes (figures 2 and 3).

Strategic Alignment for pillars is generally limited because of Pillars' 'narrow and deep' nature. They, can occur within quite small areas and are therefore more likely to be implemented as a result of an individual's efforts within an organisation. Thus some Pillar projects in Higher Education were not 'strategic' disconnected largely from the overall aims and objectives of the University. In contrast Platforms by linking up stages of value streams may provide whole system change needed by public sector organisations. The nature of 'becoming lean' in a large, public sector organisation is that a mixture of Pillars and Platform experiments will inevitably occur (Healthcare patchwork Figure 3). As organisations implement more PIA's and they develop their learning and experience, they build up a patchwork of activity toward a comprehensive lean approach.

\section{Implications for Practice}

The Pillars and Platforms metaphor helps managers to better visualise and understand alternative approaches. It provides an indicator for managers that a more strategic approach is needed to address the gaps in implementation. This strategic view helps identify weakness and risks to the overall programme of change and provides a logic about where future activities should take place to align with the organisational strategy. This was demonstrated in the Healthcare case when they started to link strategy and PIA's in their third year of implementation. Higher Education tried to take a strategic approach from the start, but they just did not have the knowledge and experience to implement the Platforms planned. The initial decision to adopt a Platform or Pillar approach to implementing lean is a choice based on what the organisation wants to achieve in terms of;

1) Resources and time within the organisation - how many people can be involved, over what time period and the political imperative - who is supportive and what is their span control.

2) The organisation's maturity in terms of lean. What is the capacity in terms of individual lean capability, existing appropriate infrastructure and strategic integration. 
3) Results needed (e.g. save money, improve quality or release capacity) and its context in terms of strategy.

\section{Conclusion}

The purpose of this paper was to outline two approaches to lean implementation and explore how well they acted as a model for organisation wide PIA based on RQ1. This addresses the need to evolve from a tool based approach centred on PIA's (Radnor and Osborne 2013) but to consider the impact on the whole organisation. The complexity of public sector organisations makes the issues of span and control highlighted by this taxonomy more likely to be an issue and so consideration of this approach is particularly relevant for the public sector organisations. Both case organisations had examples of pillars and platform that conformed to the model outlined in this paper (RQ1) although some hybrids between the models did exist. From the observation of these cases the authors were able to identify the strengths and weaknesses of both approaches (RQ2). This would enable practitioners to take a more informed selection decision when planning their activities.

Most lean transformations are constrained by the amount of resource allocated to the change team, so what happens in practice, is that the team works in different pockets of the organisation, through Pillars and Platforms, intending to instil the benefits of lean within everyone with whom they work. Pillar and Platform approaches criss-cross over organisational processes and departments until a lean patchwork is developed.

It is the authors' contention that equipping managers with a decision-making model through the appropriate selection of Pillars or Platforms in the early stages of the lean implementation will ultimately mean a more successful deployment of effort. That is to say neither Pillar nor Platform approach represents a single best way, but managers should make an informed selection based on resources available, experience of lean and the nature of improvement desired in terms of strategy.

The limitations of this research are that it focused on large public sector organisations who were in the early stages of lean maturity. While this had many advantages in enabling insights into the categories of Pillar and Platform, but it is acknowledged that further research is required to concepts in other contexts such as private sector, smaller organisations and organisations with greater experience of lean.

\section{References}

Bateman, N. \& David, A. (2002) Process improvement programmes: a model for assessing sustainability. International Journal of Operations \& Production Management, 22, 515-526.

Bumblauskas, Daniel, and Bradley Meyer. (2015) "Continuous improvement project selection and execution." Proceedings of the POMS 2015 Annual Conference, Washington DC, available: http://www. pomsmeetings. org/ConfPapers/060/060-0146.

Elger, T. And Smith, C. (1994), Global Japanization? The Transnational Transformation of theLabor Process, Routledge, London.

Eisenhardt, K. 1989. Building theories from Case Study Research. Academy of Management Review (14), pp. 532-550.

Esain A., Lethbridge S., Elias, S., Evans, B. and Davis C., (2011). The implications of Maturity of Improvement Methodologies in UK

Public Services: A pilot study. EUROMA Cambridge, July 2011.

Fillingham, D. 2008. Lean Healthcare, Improving the patient's experience. Chichester: Kingsham

Hines P, Bateman. N., Hudson P (2004) Developing a lean Enterprise: Many Ways to Skin a Cat. Proceedings of the 9th International Symposium on Logistics "Logistics and Global Outsourcing". Bangalore, Indian Institute of Management.

Hines P, Holweg, M \& Rich, N. 2004. Learning to Evolve. A Review of Contemporary lean Thinking. International Journal of Operations and Production Management 24(10)

Hines, P. And Lethbridge, S. 2008 Creating a lean University, Public Money \& Management, Vol. 28, Issue 1, pp. 53-56, February 2008 Imai, M. 1986. Kaizen: The key to Japan's Competitive Success. New York: McGraw-Hill

Joynson, S., \& Forrester, A. (1995). Sid's Heroes-Uplifting Business Performance and the Human Spirit. BBC books London

Laraia, A. C., Moody, P. E. \& Hall, R. W. (1999) The Kaizen Blitz: Accelerating Breakthroughs in Productivity and Performance, Wiley.

Miles, M. And Huberman A. 1994. An expanded sourcebook qualitative data analysis. 2nd Thousand Oaks, California: Sage Publishing

Piercy, N. And Rich N. 2009. lean transformation in the pure service environment: The case of the call service centre. International Journal of Operations \& Production Management 29(1), pp. 54-76.

Pollitt, C. And Bouckaert, G. (2004), Public management reform: a comparative analysis, ( $2^{\text {nd }}$ edition) Oxford University Press, Oxford. Radnor, Z., Walley, P., Stephens, A. and Bucci, G., (2006). Evaluation of the lean approach to business management and its use in the public sector. Edinburgh, Office of Chief Researcher, Scottish Executive.

Radnor, Z. And Osborne, S.P., 2013. Lean: a failed theory for public services? Public Management Review, 15(2), pp. 265-287

Rich, N, Bateman, N, Esain, A, Massey, L \& Samuel, D. (2006). Lean Evolution. Cambridge University Press.

Rother, M. 2010. Toyota Kata: Managing People for Improvement, Adaptiveness, and Superior Results. New York: McGraw-Hill

Senge, P.M. 1990. The Fifth Discipline. The art and practice of the learning organisation. London: Century Business

Voss, C., et al. 2002. Case Research in Operations Management. International Journal of Operations \& Production Management 22(2), pp. 195-219.

Womack, J. P. \& Jones, D. T. (2003) lean Thinking: banish waste and create wealth in your corporation, Free Press.

Yin, R. K. (1994), Case Study Research, Design and Methods, Sage Publications, Newbury Park

Young, T., et al. 2004. Using Industrial Processes to Improve Patient Care. BMJ 328, pp. 162-164. 